\title{
LAS CONSECUENCIAS DEL NIHILISMO
}

\section{THE CONSEQUENCES OF NIHILISM}

\author{
Enrique Miguel Martínez Martínez ${ }^{1}$ \\ Universidad del País Vasco
}

Recibido: 4-7-2015

Aceptado: 12-2-2016

\begin{abstract}
Resumen: Este estudio pretende aportar una imagen de lo que supone el nihilismo de Nietzsche y Heidegger a los ojos de un pensador como Gianni Vattimo. Para empezar se relatará de manera breve cuál es la concepción de ambos, en concreto que presta atención al concepto de la Verwindung. Las consecuencias que tal doctrina, apoyada siempre en el eterno retorno y la voluntad de poder, son las siguientes: la disolución del sujeto, la hermenéutica nihilista y el pensamiento débil. Todo ello se resume en la posmodernidad filosófica. El interés se reduce, por lo tanto, a intentar entender la época actual.
\end{abstract}

Palabras clave: nihilismo; sujeto; hermenéutica; posmodernidad; sociedad.

\begin{abstract}
This paper seeks to provide an image of what are the results of the nihilism inaugurated by Nietzsche and Heidegger and it is seen through Vattimo's eyes. First of all, we are going to expose shortly the conception of both of them, in particular the German concept of Verwindung. The consequences of this doctrine, always based on the eternal return and the Will to power, are the following ones: subject's dissolution, the nihilistic hermeneutics and the weak think. It can be summarized in the philosophical postmodernity. So, the interest here is reduced in an attempt to understand the present time.
\end{abstract}

Keywords: nihilism; subject; hermeneutics; postmodernity; society.

[1] 2016: Máster universitario en Filosofía, Ciencia y Valores. Euskal Herriko Unibertsitatea/ Universidad del País Vasco. 2015: Máster en Filosofía Teórica y Práctica. Especialidad de Historia de la Filosofía y Pensamiento Contemporáneo en UNED. 


\section{Introducción}

El nihilismo es una consecuencia de la declaración de la muerte de $\operatorname{Dios}^{2}$, gracias a las formulaciones tanto de $\mathrm{Hegel}^{3}$ como de Nietzsche aunque ya antes se puede considerar como implícito en el imaginario occidental. Se trata del simbolismo que desprende el sábado santo, entre la muerte biológica del cuerpo de la divinidad ocurrida el viernes y la resurrección del domingo. En otras palabras, es la precipitación del ser en la nada que, tras la ascensión a los cielos, transforma el nihilismo en una estructura trifásica de nacimiento, muerte y resurrección cuya causa es Dios. En el siglo XIX esto va más allá. El dios muerto en Hegel es la objetividad ingenua del mundo mientras que en Nietzsche es la propia cultura de Occidente cuya base es la ontología socrático-platónica y la teología cristiana. Por lo tanto, el primero muestra la necesidad de un viernes santo especulativo traducido en "el liberador cuestionamiento, la saludable relativización, la defensiva suspensión de las pretensiones absolutas del hetero-fundamento onto-teológico dominante en la tradición occidental» ${ }^{5}$. Sin embargo, permanecer en el nihilismo, que le sigue cual sábado santo, mucho tiempo no es recomendable, porque Dios ha muerto sólo durante un momento: un nuevo absoluto es inminente, aunque ahora tenga fundación terrenal. Lo mismo ocurre para el caso nietzscheano, la desvalorización de los valores es seguida por la creación de otros nuevos promovida por el superhombre, figura encarnada por el artista trágico dionisíaco.

Hasta ese momento se puede decir que la interpretación del mundo descansa sobre dos principios; por un lado, el de un fundamento del hombre ajeno a él y, por otro lado, el carácter absoluto de tal fundamento. La creación del léxico de la tradición filosófica es posible gracias a él, léxico que trae conceptos como los de ser, verdad, cosa en sí, que se resumen en la idea suprema de Dios. Sin embargo, el avance científico muestra tal fundamento absoluto como falso. El camino lleva al hombre directamente a un pensamiento liberador que le muestra como único fundamento de sí mismo su vida, su libertad y su voluntad. En definitiva, el nihilismo es una de esas aportaciones que ha obligado a la cultura a una especie de self-criticism sólo posible en Occidente debido al progreso de la técnica científica, la representación divina decadente del mundo, el progreso paulatino desde la Revolución Americana hacia sistemas políticos más democráticos y la

[2] Cuando la palabra Dios aparezca, se referirá al ente divino católico, mientras que, si aparece con minúscula, se referirá a un ente supraterrenal.

[3] Hegel, G. W. F.: Fe y saber, p. 164.

[4] Nietzsche,F.: La gaya ciencia en Obras Completas, Vol. III, pp. 802-803.

[5] Gomá, J.: Ejemplaridad pública, p. 51.

Thémata. Revista de Filosofía No53 (2016) pp.: 271-288. 
consiguiente globalización. Lo más importante estriba en que ha sido capaz de asimilar "la pérdida de eficacia de sus principios fundadores»" ${ }^{6}$. Max Weber ${ }^{7}$ atisba una evolución, mostrada por sus investigaciones científicas, desde aquella representación no cuestionable del mundo hasta un nihilismo donde los valores últimos desaparecen, con lo que infiere que tiene un carácter destinal. La eliminación de aquellos supone la última fase de la época moderna que se traduce en la iron cage donde la individualidad se pierde en pos de una masa deshumanizada que busca un sistema de administración para la sociedad masificada que constituye. Por eso no se puede obviar, en palabras de Gomá, que «modernidad y nihilismo van de la mano y mutuamente se reclaman» ${ }^{8}$.

Tanto Hegel como Nietzsche no son capaces de salir de la estructura trifásica, en tanto que ambos al entrar en la lógica nacimiento-muerte-resurrección acaban volviendo a lo mismo. Heidegger es el primero que lo nota. La razón principal que el autor de Ejemplaridad pública ofrece se resume en que aquellos dos se apartan de la finitud, de la contingencia y de la mortalidad. Hegel en su obra lo afirma, pudiendo resumir su finalidad en una subordinación de lo finito de la vida en la infinitud. El superhombre nietzscheano también tiene ese rasgo, cuando, en resumidas cuentas, finitud es una característica imprescindible del nihilismo desde el momento en que el hombre es plenamente consciente, ya sin ataduras divinas ni promesas imposibles, de su propia mortalidad. «Nada ha demostrado ser más efimero que las pretensiones eternas ${ }^{9}$, cuando el hombre es capaz de ver la historia de manera objetiva entiende que tal pretensión no sólo es absurda sino imposible, siempre y cuando no se acepte la finitud que rodea a todo lo humano. La experiencia vital es, básicamente, comprender la contingencia en la que la humanidad se halla atada.

La liberación del pensamiento permite poner en duda hasta el propio Fundamento, aquel supremo. Hay que añadir que el progreso potencialmente infinito surgido en la modernidad conlleva darse cuenta de la posibilidad de poder salvar tal contingencia, con lo cual la ciencia-técnica se convierte en el nuevo absoluto. En cualquier caso, el eterno retorno y la muerte de Dios nietzscheanos muestran un mundo sin el fundamento trascendente regulador y sin consistencia; de cualquier otro modo que no sea este, la finitud queda al amparo de la nada y el hombre debe elegir entre la civilización o la barbarie. Es decir, una vez muerto Dios el humanismo entra en crisis ya que no hay fundamento trascendente al que apelar como

[6] Ibídem, p. 46.

[7] Weber, M.: El político y el científico, pp. 79-231.

[8] Gomá, J.: Ejemplaridad Cit., p. 45.

[9] Ibídem, p. 57.

Thémata. Revista de Filosofía N53 (2016) pp.: 271-288. 
tampoco se puede esperar una reapropiación de otro principio parecido a ese. Lo que constata Vattimo ${ }^{10}$ es básico, la crisis se desata cuando el hombre se da cuenta que no puede ocupar el lugar de dios, por eso Heidegger ${ }^{11}$ entiende el humanismo como metafísica; es ella quien ha llevado a la humanitas a tal posición en tanto le ha dado un motivo fundacional para ello, pero son máscaras que Nietzsche quita tras liquidar la divinidad. El camino emprendido por este filósofo considera el avance científico culminado en la técnica, que ofrece aquella posibilidad de salvar la finitud, aunque el de Messkirch la entiende cual método deshumanizante al desplazar las ciencias del espíritu por las de la naturaleza, no sólo en el ámbito más puramente científico sino en la organización social y total de la tierra. Se pone de manifiesto, a su vez, el desplazamiento del sujeto y lo constitutivo de lo humano perdiéndose, como dice Husserl ${ }^{12}$, «en los mecanismos de la objetividad científica y luego tecnológica» ${ }^{13}$, por lo que la técnica es vista como una amenaza y es menester restaurar la centralidad de la subjetividad humana que se extiende hasta la nueva ciudad moderna.

Se trata, pues, de encontrar el modo de fundamentar la finitud cuya cara metafísica y ética se hagan patentes. El hombre es consciente de su nada y de la del otro y, encima, en la experiencia vital se muestra la finitud de su ser. Heidegger, en Ser y Tiempo ${ }^{14}$, concluye que la posibilidad humana más auténtica es comprenderse a sí mismo como finito. En este sentido, el nihilismo es un agente capaz de producir civilización. La finitud es aquella Moira en boca de Aquiles, igualadora de reyes y esclavos, cobardes y valientes, jóvenes y viejos ${ }^{15}$. Como es un elemento común a todo humano, significa que es un concepto democrático puesto en escena en aquella ciudad moderna que la técnica condiciona. En la polis actual, la llegada en tromba de la innecesariedad dibuja un individuo como entidad sujeta al cambio por otra en el momento en que ya-no-sea-útil-más. La democracia de esta época es un intento de construir y normativizar la comunidad humana sobre la base de la finitud. No tiene a lo que parecerse, porque no existe una tradición en la que apoyarse, así que es un experimento que avanza a tientas rodeado de incertidumbre. Este sistema

[10] Vattimo, G.: El fin de la modernidad.

[11] Heidegger, M.: Carta sobre el Humanismo en Hitos, pp. 259-297.

[12] Husserl, E.: La crisis de las ciencias europeas y la fenomenología trascendental.

[13] Vattimo, G.: El fin Cit., p. 36.

[14] Heidegger, M.: Ser y tiempo.

[15] Homero: Ilíada, pp. 195-197 [308-429]; el parlamento del hijo de Peleo es excepcional no sólo por la extensión, sino también por la forma de argumentación que tiene y la elaboración lingüística (atípica por los términos utilizados y la forma en que se combinan).

Thémata. Revista de Filosofía №53 (2016) pp.: 271-288. 
organizativo tiene un fundamento contingente y, además, autorreferencial por cuanto la verdad democrática no está dada por naturaleza, sino que es un producto humano convencional, pragmático y refutable.

\section{Nietzsche y Heidegger posibilitadores de un nuevo momento}

Nietzsche ${ }^{16}$ detalla una época a la que el pensamiento actual podría haber llegado ya. Es él quien ha experimentado el nihilismo en todo su esplendor, es decir, que lo ha atravesado y dejado a su espalda. Por eso el nihilismo tiene dos sentidos: pasivo y activo. Entre ambos la diferencia está en la fuerza del espíritu, que es la disolución de toda estructura objetiva a la que el individuo se remite. El activo se caracteriza por la afirmación, puesto que el carácter negativo se relaciona con el nihilismo pasivo porque en todas las formas en que acaece pretende esconder la nada que está al fondo de todo ser, valor o estructura estable. En el paso al activo, el pasivo niega la aniquilación de todo valor supremo por lo que se le llama también reactivo; reacción que es máscara ideológica por la que los ojos se cierran ante la necesidad de creación de valores y estructuras del ser, que el nihilismo activo conlleva, cubriendo el vacío dejado por la falta de estructuras objetivas. La actividad creadora se realiza, a su vez, en dos sentidos.

Por un lado, se reconoce la nada como base de significados, estructuras, valores y se da pie a la creación de nuevos valores, estructuras de sentido e interpretaciones. Por otro lado, no espera a que esto ocurra por sí mismo sino que ejerce de mano ejecutora. La razón principal por la que se debe aniquilar es su pertenencia a una manera determinada de organizar el mundo y su visión, porque toda forma de comunidad necesita de una verdad y condiciones de preservación de un sistema dentro de la interpretación de la realidad en que viven. El nihilismo activo necesitará también de esto, aunque con una diferencia básica, a saber, que las interpretaciones-valoraciones son hermenéuticas y no verdades eternas e inmutables.

Se abre, por lo tanto, una nueva forma de vida fuerte donde esta fortaleza es la garantía de vivir sin un horizonte estable al ser todo sistema de valores una creación e interpretación constante y tan efímera como el hombre mismo. Además, tales sistemas no se pueden referenciar a un criterio objetivo de validez, así que las interpretaciones siempre están en situación de desequilibrio. Sin embargo, este vitalismo no sería suficiente para acabar con la superioridad del nihilismo activo ya que «la fuerza vital implicaría una noción "metafísica" de vida que no es compatible con

[16] Nietzsche, F.: El nihilismo europeo.

Thémata. Revista de Filosofía №53 (2016) pp.: 271-288. 
el perspectivismo de Nietzsche» ${ }^{17}$. El nihilismo en general se define como "el salir a la luz de la insensatez de la existencia, de la ausencia de fines y metas, y de la esencia del ser como voluntad de poder ${ }^{18}$.

Heidegger también define este momento como un proceso que el ser recorre y en cuyo final en cuanto ser ya no queda nada. No se halla ante el nihilismo como error cometido por la metafísica que ha olvidado el ser, sino que es la posibilidad por la que «el hombre [finalmente] abandone el centro para dirigirse hacia la $X »^{19}$. Por lo tanto, el nihilismo activo engloba a uno y a otro, a ser y a hombre. Además existe concordancia entre los modos en que acontece, aunque en principio sea posible observar diferencias ya que Heidegger, más bien, considera que el motivo es la disolución del ser en el valor. Esto significa que el sujeto se apodera de los valores, así que en el nihilismo, desde su punto de vista, aquel engulle al ser. Debe llamarse al valor, valor de cambio, de manera que se entiende que el valor no desaparece sino que cambia la manera de concebirlo: Nietzsche al propugnar la muerte de Dios, la desaparición del valor de uso, transforma y libera la capacidad de los valores (de cambio) en su naturaleza potencial de posibilidad transformadora mediante indefinidos procesos.

Sin embargo, también supone dejar de lado los proyectos de reapropiación, precisamente por el mismo motivo por el que Dios se vuelve innecesario: la reapropiación se revela como superflua porque, en definitiva, el mundo verdadero se ha convertido en fábula y a esta fabulación se le asigna el carácter metafísico de mundo verdadero, mientras que el nihilista activo considera tal mundo fuera de la experiencia metafísica auténtica, autenticidad que muere con Dios. Lo humano se desacraliza, la interpretación del valor de cambio en la sociedad constituye el gran rasgo de la sociedad capitalista y tecnificada que Heidegger ${ }^{20}$ aúna en el término Ge-Stell. Aquí se da un primer Ereignis del ser donde la apropiación es transapropiación o la disolución del ser en el valor de cambio llamado lenguaje y entendido como transmisión e interpretación de mensajes. Esta disolución propicia un debilitamiento de la realidad ya que todo se da como narración, lo cual hace que aquella no sea única y se cae en un estado de permanente alienación a pesar de tener las capacidades tecnológicas de emancipación y libertad.

Para empezar, se está cimentando la ontología hermenéutica debido al anuncio de la conexión entre ser y lenguaje que hace Heidegger. Aunque a simple vista no se aprecie la contribución de este autor al ni-

[17] Vattimo, G.: Diálogo con Nietzsche, p. 211.

[18] Ibídem, p. 213.

[19] Vattimo, G.: El fin Cit., p. 23. El corchete es mío.

[20] Heidegger, M.: Conferencias y Artículos, pp. 9-37.

Thémata. Revista de Filosofía No53 (2016) pp.: 271-288. 
hilismo, existen dos aspectos que sacan a la luz tal hecho: el análisis el Dasein como totalidad hermenéutica (un rasgo posterior a Ser y Tiempo) y la definición del pensar, de algún modo meta-metafísico, como An-Denken o rememoración en relación con la tradición. En cuanto al primer término de la ecuación, el Dasein es un estar en el mundo articulado en un círculo de comprensión e interpretación que se constituye en su estructura central. No está apegado a los objetos mundanos, más bien son estos los que le son dados como instrumentos ya que se vuelven un proyecto. Las cosas son, tienen sentido, si pertenecen al Dasein de manera que le son familiares. Familiaridad significa comprensión: relación con el mundo de manera preliminar e identificación con la existencia del Dasein. Conocer es interpretar esa familiaridad preliminar con el mundo: reconocer lo conocido. Hay que tener en cuenta que el mundo así expuesto no es un esquema de categorías, se le da al Dasein en un estado de yecto (Geworfenheit) histórico-cultural inseparable de la mortalidad. Es debido a que el Dasein sólo puede ser una totalidad si se anticipa a la muerte, siendo esta la única posibilidad pura que tiene; es el factor que hace posible el resto de posibilidades debido al ritmo móvil del discurso.

Podríamos describir esta condición diciendo que el fundamento del Dasein coincide con su "falta de fundamento": la totalidad hermenéutica del Dasein está fundada sólo en relación con su posibilidad constitutiva de no ser más ahí. ${ }^{21}$

La ausencia de fundamento en conexión con el fundamento está ligada al Ereignis, evento en el que la cosa como tal se apropia a la par que se expropia. Es decir, que toda apropiación es una transapropiación. La totalidad hermenéutica se funda tanto en la posibilidad de no ser más así como en la consumación de la cosa en una referencia circular a todas las demás. Ahora se entiende mejor como el nihilismo es un dejar perder el ser cual fundamento al modo de la muerte divina nietzscheana, como la ausencia de un fundamento último regulador de la existencia. Esto, sin embargo, presenta el problema de la aparente nula nihilidad del sistema heideggeriano.

El An-Denken es la forma de pensamiento opuesta a la metafísica que explicita en las obras posteriores a la principal de 1927, pero que ya aquí expone vagamente como "decisión anticipadora de la muerte [que] debía estar en la base de la existencia auténtica» ${ }^{22}$. Se relaciona estrechamente con la muerte en tanto el Dasein se decide por ella, al recorrer la historia de la metafísica como olvido del ser, fundándose como totalidad hermenéutica cuyo fundamento es la ausencia de fundamento. El An-

[21] Vattimo, G.: El fin Cit., pp. 104-105.

[22] Ibídem, p. 106. El corchete es propio.

Thémata. Revista de Filosofía $\mathrm{N}^{\circ} 53$ (2016) pp.: 271-288. 
Denken es una apelación al Abgrund [abismo] de la mortalidad al cual el Dasein se entrega, ya que ahí reside el vínculo liberador que lo deja puesto en el pensamiento de la tradición de manera que puede superarla. Este pensamiento rememorante no tiene acceso al ser en sí, pero al recordarlo se muestra por encima del pensar metafísico que lo ha olvidado. De ahí la frase nihilista del ser como lo que no queda, la tradición es el horizonte al que se proyecta el Dasein por lo que el ser es el horizonte de apertura donde los entes se transmiten. La recuperación de la tradición no es la reconstrucción apropiativa de estados de cosas sino liberación del Abgrund y presentación, con carácter de fluidez, de los horizontes históricos: lo que se recuerda de la tradición es el sentido del ser vinculado con la muerte, que es opuesto al ser de la metafísica como energeia, esta es la debilidad del ser: la mortalidad.

En la segunda Intempestiva Nietzsche $^{23}$ aborda el problema del peso de la conciencia histórica que impide al hombre del siglo XIX producir alguna novedad. En ese momento toda producción se caracteriza por una vuelta al pasado, se trata de lo que llama la enfermedad histórica que es la decadencia de la modernidad y alude, entre otros, al cristianismo o a Sócrates; una época de la superación entendida como reemplazamiento constante de la novedad que acaba por desvirtuar la creatividad a la vez que la exige e impone como norma.

Vista así, de la modernidad no se puede salir en una simple superación ya que es una categoría propiamente moderna. Para ello hay que radicalizar las tendencias que la constituyen, lo que significa elaborar una crítica de los valores supremos mediante su reducción a los elementos que los componen. Aquellos se establecen como creencias impuestas en un momento determinado que afectan a la existencia, en principio, de la propia humanidad. El fundamento es la posibilidad de conocer las cosas en sí mismas, pero cuando el conocimiento se desvela como metaforización que parte de la cosa y va a la imagen, mediada por la interpretación hecha, la cual se pone en palabras y se le asigna un valor de verdad mediante convenciones sociales, toda noción de lo verdadero acaba por devenir en error prescindible.

En resumen, los valores no tienen valor y el fundamento no opera como fundamento: la posmodernidad filosófica queda inaugurada. Lo que en Aurora ${ }^{24}$ advierte sobre la pérdida de significado del origen, cuando se conoce de manera satisfactoria, es la función que el pensamiento posmoderno adquiere: sólo cuando volver al pasado no es la norma, el individuo puede abrir los ojos y captar la riqueza que hay en su proximidad. Los errores del pensar metafísico se vuelven errantes en la medida en que no

[23] Nietzsche, F.: Consideraciones Intempestivas en Obras Completas, Vol. I, pp. 695-748.

[24] Nietzsche, F.: Aurora en Obras Completas, Vol. III, pp. 513-514. Fragmento 44.

Thémata. Revista de Filosofía $\mathrm{N}^{\circ} 53$ (2016) pp.: 271-288. 
hay un fundamento último con el que compararlos, no se trata de disolverlos sino de reconocerlos como partes constituyentes del mundo gracias a las cuales la realidad es tan rica en matices.

Es cierto que Nietzsche no utilizaría nunca este término, pero lo que se acaba de exponer presenta la estructura de lo que Heidegger llama Verwindung y que es la esencia de la posmodernidad filosófica según Vattimo. Cabe resaltar que esta posición es muy próxima al An-Denken en tanto una vuelta a la consideración del pasado anclado en la metafísica. En este sentido, ella misma es un rastro de una enfermedad a la que el hombre se resigna (Verwindet). La Verwindung del Ge-Stell, que es la forma final de la metafísica, es la posibilidad de un cambio que lleve a un Ereignis fuera o más allá de la propia metafísica, aunque el individuo no se entrega sin más ni a la metafísica ni al Ge-Stell. Verwinden es la segunda acepción, tras Verwindet, de la Verwindung, que no es tanto resignación como dis-torsión. Quiere decir que metafísica y Ge-Stell no pueden ser consideradas como la posibilidad de cambio, algo a tener en cuenta tras la Kehre: si en Ser y Tiempo el olvido del ser es la tarea del hombre en cuanto a rememorar (Andenken) el ser, después de 1946 el olvido del ser no deja de estar inscrito en el mismo ser: por eso la rememoración (An-Denken) no capta el ser dado en la presencia, no se puede captar del todo. «El ser se da aquí sólo en la forma de Geschick (el conjunto del envío y el destino) y de la Ueberlieferung (la trans-misión)» ${ }^{25}$. La metafísica como Ge-Schick se sobrepone a la vigencia de la metafísica cual muerte de Dios, no hay verdad última o fundamento absoluto sino horizontes históricos abiertos que no son sólo la historia de los errores sino el ser mismo. La Pietas sería la actitud idónea con la que hacer frente al pasado y al presente.

De modo que la hermenéutica heideggeriana vincula el Andenken y la Verwindung y se debe tomar en su sentido ontológico para determinar que el ser es la trans-misión de aperturas y de destino, que constituyen la posibilidad de la humanidad de acceder al mundo. El Andenken tiene así una dimensión emancipadora y no capta ningún fundamento, por lo que uno de los caracteres del pensamiento de la posmodernidad será un pensar del revivir o rememorar. El imperativo de ir más allá de la metafísica, que sigue Heidegger ${ }^{26}$, lo acompaña de «un trabajo que tiene por contenido principal la metafísica y su errar» ${ }^{27}$, lo que en comparación con la Verwindung parece que cae en una repetición y distorsión, siendo el camino que la hermenéutica posterior, en particular la gadameriana, ha seguido. Se trata del segundo carácter del pensamiento posmoderno, el pensamiento de la contaminación.

[25] Vattimo, G.: El Fin Cit., p. 153.

[26] Heidegger, M.: El fin de la filosofía.

[27] Vattimo, G.: El Fin Cit., p. 156.

Thémata. Revista de Filosofía N53 (2016) pp.: 271-288. 
Por último, el tercer carácter sería un pensamiento del Ge-Stell. Es un concepto que presenta aquella seguridad alcanzada por la manipulación técnica de la naturaleza debido a lo cual Dios ya no es necesario según Nietzsche. En el Ge-Stell la metafísica se cumple como «la organización total de la tierra por obra de la técnica» ${ }^{28}$. El objetivo sería el descubrimiento de las posibilidades posmetafísicas de la técnica como continuidad de la técnica y la tradición del pasado mediada por la Verwindung. En el Ge-Stell hombre y ser se reúnen por primera vez, por eso es el primer centelleo del Ereignis. El Ge-Stell consigue disolver la distinción entre sujeto y objeto, abriendo la posibilidad de la entrada de los mass media como interpeladores entre el individuo y la realidad. En conclusión, la posibilidad de transgresión de lo moderno a lo posmoderno se da a través de una ontología débil que recorre los estados de aceptación-convalecencia-distorsión.

\section{Hermenéutica nihilista}

La hermenéutica considerada por Vattimo es la representada por Heidegger, como la interpretación del sentido del ser, y por Gadamer ${ }^{29}$, como la interpretación pensada desde el lenguaje, de modo que ontología y lingüisticidad (Sprachlichkeit) son sus dos aspectos más notables. Los hechos dejan su lugar, por lo tanto, a las interpretaciones. Esta disciplina no es autónoma hasta el siglo XX enmarcándose dentro de la problemática de la confrontación entre las ciencias del espíritu y las de la naturaleza del XIX, así que no es traspasable la verdad científica objetiva de las segundas a las primeras. Sin embargo, no es sólo el método positivista-científico el guardián de tal verdad; se debe a que "no hay experiencia de verdad sino como acto interpretativo» ${ }^{30}$, significa que la correspondencia proposición-enunciado-estado de cosas es posible porque los dos últimos se hallan en una relación previa que provoca una apertura cuya verdad o falsedad dependen de otra más originaria. Es decir, aquella experiencia de la verdad se da gracias a la precomprensión que el hombre como ser-en-el-mundo tiene de lo mundano; la influencia fenomenológica y neokantiana es visible aunque superable, tal precomprensión no es constitutiva de lo humano. El principal problema se encuentra en su pretensión metafísica de fundamentar una verdadera y última descripción de la estructura interpretativa de la existencia humana, consideración teleológica y cientificista

[28] Ibídem, p. 158.

[29] Gadamer, H-G.: Verdad y Método.

[30] Vattimo, G.: Más allá de la interpretación, p. 41.

Thémata. Revista de Filosofía No53 (2016) pp.: 271-288. 
que se encuentra en el pensamiento moderno. No caer en esto es tener muy en cuenta la finitud e historicidad de la precomprensión.

Heidegger, pues, abre el horizonte donde la verdad se muestra como histórica y que imposibilita pensarse como una mera descripción de la estructura del existir. No obstante, entender la hermenéutica cual simple interpretación de las posibles interpretaciones que el horizonte abre es caer en aquel contratiempo de nuevo. Historicidad y finitud deben llevar a tal filosofía a verse como una metateoría del juego de las interpretaciones. En efecto, la manera de superar la metafísica acechante es tener por provisional la interpretación dada, siendo válida hasta que otra la consiga desmentir. De manera que la hermenéutica se presenta "como la interpretación filosófica más persuasiva de una situación» ${ }^{31}$. Es la filosofía de la modernidad. Hay dos motivos para decir tal cosa. El primero es que la hermenéutica tiene conciencia de su historicidad, ya que su verdad depende de la interpretación y asunción de responsabilidad de los hechos que acontecen en la época, y de su finitud, en tanto la interpretación es válida si y sólo si no hay otra mejor. La segunda razón es el nihilismo, puesto que sus condiciones de posibilidad, la muerte de Dios y la fabulación del mundo, sirven al propósito del juego interpretativo. Se debe a que es ese el momento en que el sujeto entiende que es portador de un lenguaje histórico-finito que es condición de acceso a sí mismo y al mundo.

Una de las consecuencias de la conexión entre nihilismo y hermenéutica, plasmada en la imposibilidad de una verdad absoluta y objetiva, es la concepción del ser que ya no será un objeto o estado de cosas sino un evento o suceso. Vattimo prefiere pensar que no se trata de un retorno al ser que Heidegger concluye, más bien de un debilitamiento o acordarse de ese olvido sin volver a hacerlo presente; la razón es mantener la diferencia ontológica, no identificar ser y ente, para lo cual recordar el olvido es lo mismo que no perder de vista la unión entre hermenéutica y nihilismo. La hermenéutica nihilista, en definitiva, tiene sentido en el marco de la disolución de la verdad objetiva absoluta. Son tres los rasgos de la hermenéutica, «en tanto que racionalidad espiritual de la condición postmoderna» ${ }^{32}$ : límite, retorno y esperanza cuyas caras son Heidegger, Gadamer y Vattimo.

En cuanto límite, la hermenéutica como recuperación del pasado debe acudir a Grecia y, en concreto, a la teología racional, cuya crítica recupera Nietzsche ${ }^{33}$, puesto que el hombre ocupa el lugar de los dioses que no eran (y por eso se rechazaron). El límite es la condición de posibilidad de la diferencia ontológica y, por lo tanto, es ontológico también: es lo que

[31] Ibídem, p. 48.

[32] Arenas-Dolz en Oñate, T.: El retorno teológico-político de la inocencia, p. 107.

[33] Nietzsche, F.: El nacimiento de la tragedia en Obras Completas, Vol. I, pp. 329-438.

Thémata. Revista de Filosofía $\mathrm{N}^{\circ} 53$ (2016) pp.: 271-288. 
constituye el orden y a lo que lo universal se refiere, de modo que es una medida que marca el nacimiento de la polis en contraposición a la phýsis. La pietas muestra que no hay pasado agotado o ya-finalizado, es una comprensión del tipo ontológico modal e histórico, a partir de la experiencia estética de la obra de arte como reinterpretación del pasado siempre-abierto. La hermenéutica en su rasgo ontológico de límite busca recuperar todo pasado silenciado, en lo que Nietzsche hace especial hincapié, pues si son apartados esos pasados, el futuro es algo decadente cuya tradición es una losa de mucho peso; esa recuperación es el inicio del eterno retorno. La finitud, además, es la condición de posibilidad del ser-diferencia que es capaz de abrir esta última al pensamiento hermenéutico.

Lo que la hermenéutica, en definitiva, explicita es la aceptación por parte del sujeto de su mortalidad y finitud. Es decir, el desplazamiento del centro hacia fuera que el filósofo de la Universidad de Turín expone no es más que esa asimilación o, en palabras de Gomá ${ }^{34}$, el proceso de cambio entre estadios. Lo único no-relativo es el límite porque es capaz de abrir esa diferencia como un criterio más del espacio-tiempo sociocultural basado en la interpretación plural, para lo cual es imprescindible la experiencia puesto que ni existe comprensión ni praxis ética que aplicar a la vida sin el Verstehen gadameriano.

La verdad tecno-científica no es suficiente más que para el control de lo ente, pero no para aquella comprensión e interpretación. Tal y como Empédocles recoge tanto de Parménides como de Heráclito, al comprender le pertenece el nombre del límite como philía; esta verdad del amor es el límite para Vattimo. El de Éfeso saca a la luz que tal límite es el de las diferencias que se piensan y dicen en plural, además de apuntar de manera perfecta que sólo es el amor el que establece esas diferencias y mantiene la distancia entre los extremos vida-muerte. Heidegger rescata esto y se da cuenta que por debajo del lógos están la philía y el eros cuyo lenguaje comunal es condición de posibilidad de la mismísima polis. El origen del lenguaje es el amor, en concreto, como observa Gadamer, en la conversación con aquellos que ya no están. Es decir, es la asunción del límite que nos hace ser lo que somos: seres finitos. Se abre entonces, en esa conversación, el límite por el otro lado que busca el perdón. Aristóteles ${ }^{35}$ sitúa la finalidad de la tragedia ática en la comunicación entre los lados del límite que busca la condonación de lo pasado, por lo que genera un lazo social y catarsis entre el temor y la esperanza. La apertura del otro lado del límite es posible gracias al retorno.

Nietzsche es bien consciente de que el cambio cultural que busca sólo se da si se vuelve a considerar lo que de Grecia se silencia por el cristianis-

[34] Gomá, J.: Aquiles en el gineceo, pp. 65-108.

[35] Aristóteles: Poética.

Thémata. Revista de Filosofía No53 (2016) pp.: 271-288. 
mo; entre otras cosas, un renacimiento de la inocencia, aplastada por la culpa religiosa, del arte como philía que suponga el restablecimiento del lazo social y el perdón, de la paz civil en sentido de renacimiento cultural trágico. Para ello es necesario el retorno de la diferencia característica griega y no de la visión del mundo totalizante cristiana, quienes malinterpretan ese sentido cual historia salvadora de la humanidad en tanto que superadores de pasados paganos. No se trata de una descripción del tiempo físico, sino del deseo, de la philía, de la repetición de identidades diversas. Por lo tanto, la hermenéutica y posmodernidad rescatan «la dimensión olvidada de lo otro constituyente de lo humano» ${ }^{36}$. Si bien el retorno no es una forma física del tiempo, sí que altera la temporalidad en sentido progresivo al implicar una vuelta al pasado. La esperanza es la que ata el nudo gordiano temporal por cuanto supone una remisión al futuro donde, por un lado, se establece el vínculo dialogal y, por otro, se cumple el retorno como philía.

Nietzsche es, según Vattimo, precursor de la ontología hermenéutica, en tanto aquel considera la interpretación como una característica fundamental de la existencia humana de manera que puede llegar a constituir un primer paso en la tarea de dejar atrás la metafísica occidental. Para ello dos obras se vuelven necesarias, la segunda Consideración Intempestiva ${ }^{37}$ y Sobre verdad $y$ mentira en sentido extramoral ${ }^{38}$. La imagen de la historia como almacén de máscaras sin una linealidad progresiva unitaria de los acontecimientos muestra que no hay hechos sino interpretaciones, por lo tanto, el filósofo italiano entiende la tensión entre este no-historicismo y el historicismo como ejemplo de la hermenéutica existente en Nietzsche. Desenmascara toda noción metafísica que ofrece la posibilidad de llegar a conocer la esencia verdadera de la realidad; es decir, tampoco se puede afirmar la existencia de una Verdad. Lo que mueve a Heidegger ${ }^{39}$ a considerar a Nietzsche como último pensador metafísico estriba en que, al final, eterno retorno y voluntad de poder se convierten en esencia última del mundo, que no es verdadero sino fábula pero que en poco se acaba por diferenciar del precedente. La ontología hermenéutica se halla inmersa en esa tensión entre la universalidad de la interpretación y la posibilidad de adquisición de un sentido metafísico en nociones como las anteriores. Para no caer en esto, hay que tener en cuenta el nihilismo en su sentido activo, no sólo basta con entender que todo valor ha quedado desfundamentado sino que el hombre queda desplazado hacia un lado.

Tal desplazamiento supone una liberación, puesto que ya no se depende de una esencialidad o necesidad de fundamentación última, ahora

[36] Oñate, T.: El retorno teológico-político de la inocencia, p. 122.

[37] Nietzsche, F.: Consideración Cit.

[38] Nietzsche, F.: Sobre verdad y mentira en sentido extramoral, pp. 15-38.

[39] Heidegger, M.: Nietzsche.

Thémata. Revista de Filosofía Nº53 (2016) pp.: 271-288. 
es el individuo quien tiene la misión de crear nuevos valores. El nihilismo pasivo, que parte también de la muerte de Dios, sigue un camino totalmente diferente del ocultamiento de la nada que está en el fondo de todo ser y que el activo asume en su tarea de desenmascaramiento. La creación de nuevas estructuras estables no es más que interpretación, hermenéutica, aunque corre el riesgo de equipararse con la simple experiencia vital, de ahí que ella misma no pueda dejar de ser ontológica, que no sólo atañe al hombre sino al ser, y nihilista activa, porque toda creación es válida hasta que otra mejor la sustituye y no tiene la pretensión de ser eterna. Además, es preciso tener en cuenta la historicidad de modo que el último atisbo metafísico quede descartado, por ello la desvalorización de todos los valores y la fabulación del mundo, siendo esta también una interpretación, son consecuencias del curso de los eventos, que sólo es posible narrar e interpretar desde una perspectiva nihilista. A la consideración de la hermenéutica hay que añadir la posición de moderación desarrollada por Nietzsche que el nihilista activo debe tener.

\section{Pensamiento débil}

Tanto el pensamiento dialéctico como el de la diferencia son característicos del pensamiento débil. En cuanto al primero, la dialéctica aparece caracterizada, según Sartre ${ }^{40}$, como totalidad y reapropiación; se apega, además, a la noción hegeliana de la verdad que Vattimo alarga hasta la pretensión de las ideologías de construir una visión objetiva del mundo, que es errónea ya que el punto de vista desde el que parten es parcial. Reconstruir la totalidad es reapropiarla en tanto tal visión se despliega completamente libre de componente ideológico, para lo que Sartre determina que se da sólo en un contexto de revolución donde teoría y praxis se vuelven uno dentro de la comunidad de individuos que adopta una perspectiva común. Esto acaba por mostrar que la tesis de Benjamin ${ }^{41}$ según la cual la historia la dictaminan los ganadores, quienes posibilitan y fundamentan la concepción progresiva de la historia por la que la revolución llega como decisión de tomar voz de todas aquellas minorías que, en su momento, perdieron.

La revolución recuperaría el pasado de los aplastados por los dominadores. Sin embargo, es imposible recuperar la totalidad del pasado excluido; es más, la revolución misma es un acto excluyente, para empezar, del que hasta el momento es el dominador. La revolución «es, ahora, el derecho de una nueva fuerza, que se actualiza a través de nuevos actos

[40] Sartre, J. P.: Crítica de la razón dialéctica.

[41] Benjamin, W.: Sobre el concepto de historia en Obras, Libro I Vol. 2, pp. 305-318.

Thémata. Revista de Filosofía №53 (2016) pp.: 271-288. 
de exclusión» ${ }^{42}$. Poner el acento en esas micrologías saca a relucir la crisis del pensamiento dialéctico, porque a pesar de buscar la reapropiación de la totalidad de las voces reprimidas, son ellas las que se dan cuenta que se introducen en una lógica totalizadora propia de las clases antaño dominantes. Planea sobre la dialéctica un halo de disolución donde se inserta el pensamiento de la diferencia.

La conceptualización de la metafísica tras la muerte de Dios se vuelve innecesaria garantía tranquilizadora ante las vicisitudes de la naturaleza y, sobre todo, insuficiente frente a los avances de la técnica. Para evitar la transformación del descubrimiento de la vacuidad de la metafísica en una nueva, no queda más remedio que la remisión a Heidegger. Él desarrolla la concepción del ser como presencia fruto del olvido ya que ha sido relegado a la posición del ente y, sin embargo, son diferentes ontológicamente. El ser no es porque lo que es, es el ente; el ser se diferencia del ente porque aquel es un suceso o evento histórico-cultural donde estos pueden ser aprehendidos por el Dasein. El ser, por lo tanto, es transmisión (Überlieferung) y envío (Ge-Schick), el mundo se experimenta de este modo desde los horizontes que estos dos abren a través de los mensajes e individuos del pasado. Ser y lenguaje quedan unidos, el pensamiento de la diferencia conlleva esa disolución dialéctica en tanto que liberado el ser de su carácter presencial la historia es apropiable por, disuelta en, todos sus integrantes.

Despojar de ese rasgo al ser supone, además, su conversión en finito, de ahí su debilitamiento. Junto con la herencia de la dialéctica, la diferencia ontológica se vuelve ontología y pensamiento débiles gracias a la Verwindung. Esta supone el rebasamiento de la metafísica a la par que un proyectarse hacia el futuro. Aquí se encuentra el carácter disolutivo de la dialéctica unido al pensamiento de la diferencia, que piensa el ser como Überlieferung y Ge-Schick y, en definitiva, se puede entender como el AnDenken o rememorar el ser sin hacerlo presente sino recordado como un ya-sido. El ser es un destino, no ya la metafísica: de ahí la Kehre. No hay categorías de acceso al ser salvo las objetivantes de la metafísica, en este caso la Verwindung fuerza a tomarlas pero sin dejar de lado otras que pueden ser más apropiadas, con lo que se elimina de todas ellas «la pretensión de acceder a un ontos on ${ }^{43}$. Las categorías devienen en valores heredados por la pietas que recoge la voz del pasado, es decir, que muestra la finitud y caducidad del ser. Por este presupuesto se tiene que empezar a considerar la ontología débil. La diferencia entre ser y ente se da en lo constitutivo del segundo como ac-cadere o suceder, como una apertura configurada en la

[42] Vattimo, G. y Rovatti, P.A.: El pensamiento débil, p. 24.

[43] Ibídem, p. 33.

Thémata. Revista de Filosofía N53 (2016) pp.: 271-288. 
anticipación de la muerte del ser. El Ereignis muestra tal cosa, por lo que el An-Denken será la rememoración de la finitud.

El problema al que se enfrenta el pensamiento débil es la concepción de la verdad que, en el escrito de Heidegger De la esencia de la verdad ${ }^{44}$, tiene dos significados. Por un lado, la estricta adecuación entre proposición y cosa; por otro, el de la libertad o la posibilidad de adecuación de cualquier cosa. A su vez, esta segunda bien podría ser la de las realidades singulares verdaderas que no apela al acceso más originario del ser sino que son caminos de experiencia de la propia verdad. O bien, sería la libertad que los individuos en una sociedad conocen. En este sentido se podría hablar de los juegos del lenguaje wittgensteinianos, donde la verdad-adecuación se verifica en base a las reglas que rigen dicho juego y se sitúa en la apertura del horizonte del diálogo, ya sea entre individuos, grupos o épocas. Cabe, por lo tanto, inferir que la naturaleza de la verdad es hermenéutica para la ontología débil; por eso el ser no es, sino que se transmite ateniéndose a la concepción heideggeriana de la Verwindung. La hermenéutica tiene el sentido de re-pensar lo ya sido-dicho que se constituye en el auténtico pensamiento. La libertad es condición de posibilidad de la verificación y el acuerdo llevados a cabo dentro de un horizonte, donde existen vínculos y predisposiciones que son la sustancia de la pietas. La verdad, asimismo, se constituye sólo en el proceso interpretativo, no es resultado de la interpretación.

Esta concepción ontológica débil tanto del ser como de la verdad borra de un plumazo la supremacía que la metafísica otorga al pensamiento, de modo que no es oportuno rechazar el legado que esta transmite sino sólo su pretensión unitaria y central. Se trata de una red donde la alteridad, las voces silenciadas por los dominadores, consigue su espacio de interacción. Por consiguiente, la ontología hermenéutica está abierta al Otro y se debe entender que la historia en su pluralidad no es reconocida por la modernidad más que como ahistoria puesto que «la revolución de la ilustración moderna europea consiste en cortar con la plural historicidad de sus pasados culturales en nombre de la única Historia-Ser $\rangle^{45}$ que es la de la Salvación cristiana.

Así pues, tanto la muerte de Dios como el debilitamiento del ser son los diferentes nombres para denominar la kénosis vattimiana. Esta exige a la hermenéutica recorrer el camino hacia el origen para dar voz a aquellos pasados en una suerte de retorno (eterno) a la historia de la salvación. Para dar carpetazo a una hermenéutica reducida a mera estética clasicista, el filósofo italiano preconiza «una radicalización de la hermenéu-

[44] Heidegger, M.: De la esencia de la verdad en Hitos, pp. 151-171.

[45] Oñate, T.: El retorno griego de lo divino en la postmodernidad, p. 41.

Thémata. Revista de Filosofía ํ53 (2016) pp.: 271-288. 
tica gadameriana ${ }^{46}$ que restrinja la pietas a la bondad cristiana fruto del sacrificio del hijo de Dios, pues este hace posible la continuidad dialogal entre la propia hermenéutica y la secularización de la crítica moderna en sentido disolvente. Tal sacrificio se traduce en la consumación del vínculo que Dios adquiere con su pueblo en forma de amor debilitando, de aquella manera, la violencia del acto sacrificial en la cruz.

\section{Conclusión}

El camino iniciado por Vattimo, sobre todo, a través de la ontología hermenéutica, muestra que la posmodernidad filosófica está en proceso de cambio. El nihilismo activo se debe dirigir hacia una crítica del capitalismo y el neoliberalismo, ya que se han instaurado como dogmas insuperables. Un debilitamiento de la verdad, posibilitada por el pensiero debole, puede hacer que la hermenéutica ponga en el punto de mira que todo poder es cuestión de interpretación ideológica dominante. Se consigue, así, poner el acento sobre las voces arrasadas por este último y se superan incluso hasta las fronteras, en lucha contra lo cual el pueblo se une al negársele, vía discurso oficial, un futuro mejor.

La hermenéutica ontológica no se debe quedar en otro discurso más, sino que debe entrar en la existencia misma. Desde una reflexión a su alrededor, junto con los avances que las TICs han supuesto, las posibilidades de sobreponerse a la dominación son más fuerte que nunca. Aunque, sin perder de vista que, no existen hechos sino interpretaciones.

\section{Bibliografía}

Aristóteles: Poética. Madrid: Editorial Gredos, 1999.

Benjamin, W.: Obras, Libro I, Vol. 2. Madrid: Abada Editores, 2008. Gomá, J.: Aquiles en el gineceo. Valencia: Editorial Pre-Textos, 2007. - $\quad$ Ejemplaridad pública. Madrid: Editorial Taurus, 2009.

Hegel, G. W. F.: Fe y saber (Glauben und Wissen), tr. Vicente Serrano. Madrid: Biblioteca Nueva, 2000.

Heidegger, M.: Conferencias y Artículos (Vorträge und Aufsätze), tr. Eustaquio Barjau. Barcelona: Editorial Serbal, 1994.

Hitos (Wegmarken), tr. Aurturo Leyte y Helena Cortés. Madrid: Editorial Alianza, 2000.

- Nietzsche 2 Vols. (Nietzsche), tr. Juan Luis Vermal. Barcelona: Editorial Destino, 2000.

[46] Ibídem, p. 44.

Thémata. Revista de Filosofía N53 (2016) pp.: 271-288. 
Homero: Ilíada. Madrid: Editorial Espasa, 2007.

Husserl, E.: La crisis de las ciencias europeas y la fenomenología transcendental (Die Krisis der Europäischen Wissenschaften und die Transzendentale Phänomenologie), tr. Jacobo Muñoz. Barcelona: Editorial Crítica, 1990.

Nietzsche, F.: El nihilismo europeo: Fragmentos póstumos (otoño 1887). Madrid: Biblioteca nueva, 2006.

- $\quad$ Sobre verdad y mentira en sentido extramoral (Über Wahrheit und Lüge im aussermoralischen Sinne), tr. Luis M. Valdés. Madrid: Editorial Tecnos, 2007.

- $\quad$ Obras Completas, Vol. I. Madrid: Editorial Tecnos, 2011.

- $\quad$ Obras Completas, Vol. III. Madrid: Editorial Tecnos, 2014.

Oñate, T.: El retorno griego de lo divino en la postmodernidad. Madrid: Editorial Alderabán, 2000.

- $\quad$ El Retorno teológico-político de la inocencia. Los Hijos de Nietzsche en la Postmodernidad II. Madrid: Editorial Dykinson, 2010.

Sartre, J. P.: Crítica de la razón dialéctica 2 Vols. (Critique de la raison dialectique (précédé de Questions de Méthode)), tr. Manuel Lamana. Buenos Aires: Editorial Losada, 1963.

Vattimo, G.: El fin de la modernidad. Nihilismo y hermenéutica en la cultura posmoderna. (La fine della modernità), tr. Alberto L. Bixio. Barcelona: Editorial Gedisa, 1990.

- $\quad$ Más allá de la interpretación (Oltre l’interpretazione), tr. Pedro Aragón Rincón. Barcelona: Editorial Paidós Ibérica, 1995.

- Diálogo con Nietzsche. Ensayos 1961-2000. (Dialogo con Nietzsche), tr. Carmen Revilla. Barcelona: Editorial Paidós, 2002.

Vattimo, G. y Rovatti, P. A.: El pensamiento débil (Il pensiero debole), tr. Luis de Santiago. Madrid: Editorial Cátedra, 1988.

Weber, M.: El político y el científico (Politik als Beruf, Wissenschaft als Beruf), tr. Francisco Rubio Llorente. Madrid: Editorial Alianza, 1986. 